\title{
COORDINATION PROBLEMS IN ENGINEERING DEGREES
}

\author{
M. Cortés-Reyes, C. Fernandez-Gago, A. Diaz, J. M. Rosas \\ University of Málaga (SPAIN)
}

\begin{abstract}
This work focuses on the analysis of the satisfaction level of the learning for the students of the degree of Chemical Engineering (CE), Engineering of Industrial Technologies (EIT), Engineering of the Energy (EE) and Engineering in Industrial Organization (EIO), Computer Science (CS) and Telecommunications Engineering (TE). A methodology has been proposed for monitoring and evaluating the correct coordination of execution of how to implement the possible changes in the syllabus and guidelines of the above degrees. This methodology consists of a revision of the syllabus of all the subjects of first course; the establishment of indicators to easily identify the subject requiring improvements, data gathering from students by surveys and interviews and analysis of the results.

From the data obtained with the participation of more than 700 students, some changes have been proposed to the coordinators of the degrees, involving temporary schedule of contents and guideline modifications. In addition, the indicators are applicable to other degrees, improving the system of coordination at different levels.
\end{abstract}

Keywords: enhancing learning, undergraduate students, coordination, previous knowledge, overlapping

\section{INTRODUCTION}

Nowadays, engineers have an important role in our society and, in consequence, the careful development of their appropriate academic training process is essential. In order to ensure a high education level, the suitable coordination has to be tackled down in the definition of the different degrees, and it has to be done at horizontal, vertical and transversal levels, between lecturers and professors of the same subject; department and group, respectively.

In Higher Education, the methods to measure the quality are not easy [1]. Sometimes it seems that the objectives for the responsible of the teaching quality control are focused on the verification of the process in which professors fill out the documents and the achievement of success rates than on ensuring the best content in the guidelines and the proper organization of the degrees.

The implementation of the so-called "Bologna process" on the Spanish University has required a great effort on the part of all the actors involved: lecturers, students, academic organization bodies, etc. After this complex process of reorganization, some issues might have gone unnoticed, perhaps because the guidelines of the courses do not detail the contents in depth or maybe due to deviations during the implementation of the guidelines.

As is well known, communication is central to the teaching process [2]. Sometimes there is an absence of communication between professors, not only from the same area but also from the same course. On the other hand, the students are satisfied with passing the subjects and, maybe due to fear or embarrassment, are not able to report the lack of contents, deviation from the guidelines or the duplicities between the courses. Most of professors try to improve their teaching skills and motivate the students by using new technologies instead of thinking about the basis problems. The use of these technologies pretends the improvement of the teaching and are helpful to enhance the ability of learning [3]. However, it is not enough to achieve the high quality level for the engineers without a suitable programming of their education. For that, this work is focused on the study of the coordination problems in engineering degrees, discovering the satisfaction at both students and professors level and proposing corrective measures for the first year students in 6 different degrees in engineering implanted in the University of Malaga. 


\section{METHODOLOGY}

The analysis of the different degrees involved in this work was carried out by using the following methodology:

a) In an initial step, a revision of the curricular guidelines of all the subjects from the first course of the different engineering degrees was performed in order to detect possible overlaps, duplicities and/or lack of contents, which must be previously acquired.

b) The establishment of indicators to easily identify the subjects requiring improvements in their coordination and/or the need of previous knowledge.

c) Data gathering from students of the first-course of the degrees by surveys and personal interviews. The survey has been widely used as research procedure, since it allows the fast obtaining of data and the efficient processing of them [4]. A general survey, available to students through "Google Docs", was proposed, where students must answer to questions related to the conditions of access to University of Malaga, such as their corresponding marks and the modality of the bachelor studied, at the same way than Cea [5]. As far as the degree is concerned, the students answered several questions regarding the possible presence of content duplicities, overlappings and/or the need of previous knowledge required to complete the different subjects, from two different points of view: contents acquired in their bachelor or contents which must be learnt along the degree in other subjects. Furthermore, they have to provide specific information about which subject and/or content issues must be solved. When the information was not complete enough, personal interviews were also performed with the goal of obtaining more accurate information.

d) Analysis of the collected results. In this step, a relationship between the curricular guidelines and the information derived from the students was established. The results were analyzed w.r.t. each of the questions and w.r.t the different degrees.

e) Interviews with the corresponding coordinators of the degrees to expose the obtained results in order to avoid the issues found.

\section{RESULTS}

An important issue addressed in this work was the presence of content duplicities due to a wrong coordination among professors of different subjects for the same group; or even caused by an incorrect temporary organization of contents. In this last sense, some subjects can use contents taught in others, but due to an inadequate temporary organization, one professor needs to provide an overview about a specific topic, before the professor in charge of these contents explains them.

After the analysis of the questionnaires we have detected difficulties in all the degrees under evaluation related to the lack of previous knowledge as shown in Figure 1. When the students were asked about the necessity of having knowledge acquired before attending the course, in all the degrees the students answered "yes" in a percentage close or higher than $50 \%$, reaching in some situations percentages close to $80 \%$.

Industrial Technology Engineering

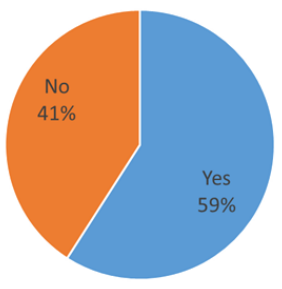

Computer Science

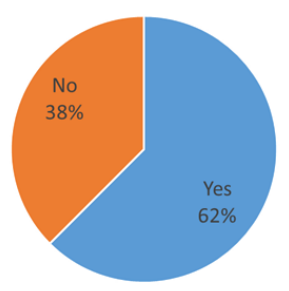

Engineering in Industrial Organization

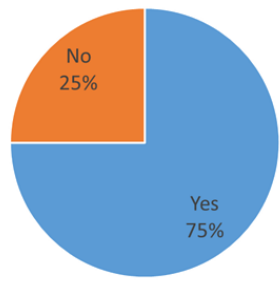

Chemical Engineering

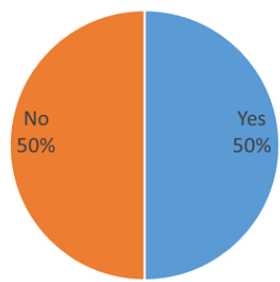

Telecommunication Engineering

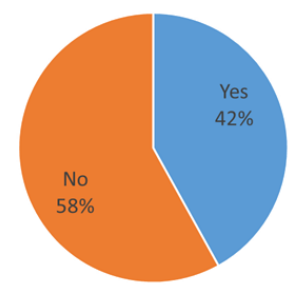

Energy Engineering

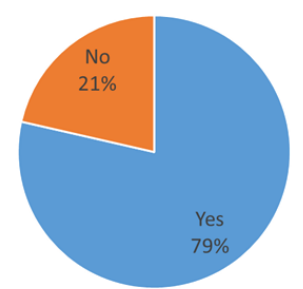


Figure 1. Perception of the need for prior knowledge

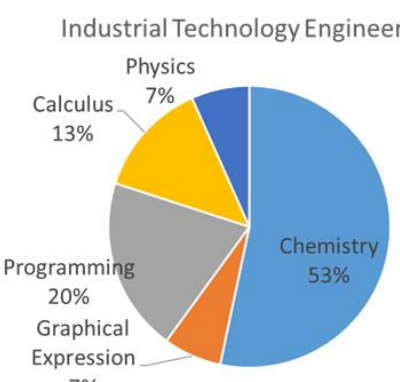

$7 \%$

Computer Science

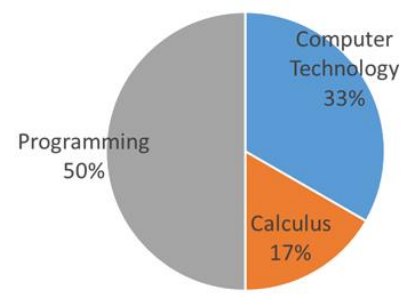

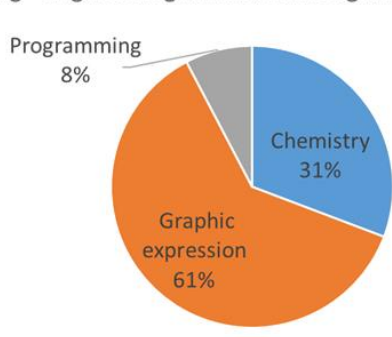

Chemical Engineering

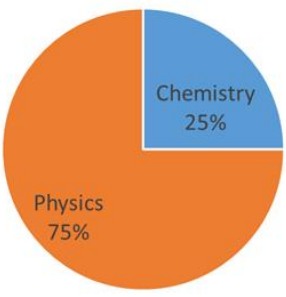

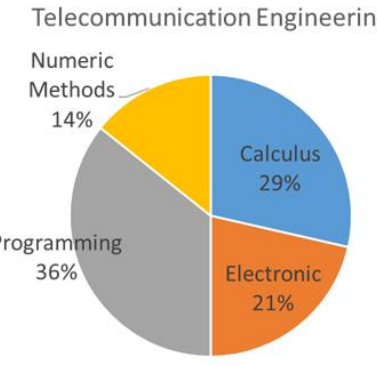

Energy Engineering

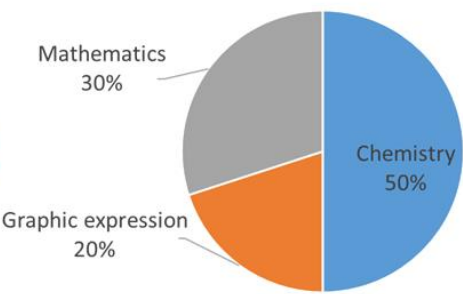

Figure 2. Identification of courses with problems related to previous knowledge

After the analysis of the questionnaires we have detected difficulties in all the degrees under evaluation related to the lack of previous knowledge as shown in Figure 1. When the students were asked about the necessity of having knowledge acquired before attending the course, in all the degrees the students answered "yes" in a percentage close or higher than $50 \%$, reaching, in the case of the Chemical Engineering degree, a percentages close to $80 \%$.

Figure 2 identifies the specific subjects where the students lack of previous knowledge. Programming, Electronics and Computer Technology are not core subjects in high schools, thus limited background for some students can be expected. However, the base knowledge required for Calculus, Numerical method, Mathematics, Chemistry, Physics and Graphic Expression should be general as these subjects are essential for the curriculum of students targeting Engineering. However, derived from the organization of the subjects in high school, for which Chemistry and Physics are optional subjects, the students present great deficiencies in these areas. Therefore, we can conclude that these subjects should be compulsory subjects in high school.

A different situation occurs in the case of subjects in the area of mathematics. The advanced mathematics that are needed in engineering careers are compulsory subjects in the two high school modalities mainly studied by engineering students, as shown in Table 1. In this case, mathematics concepts should be reinforced in pre-university courses.

Table 1. High school modality of the students analyzed from the different engineering degrees

\begin{tabular}{|l|c|l|l|l|l|l|}
\hline $\begin{array}{l}\text { High school } \\
\text { modality }\end{array}$ & $\begin{array}{l}\text { Industrial } \\
\text { technology } \\
\text { Eng. }\end{array}$ & $\begin{array}{l}\text { Eng. in } \\
\text { industrial } \\
\text { organization }\end{array}$ & $\begin{array}{l}\text { Telecomm. } \\
\text { Eng. }\end{array}$ & $\begin{array}{l}\text { Computer } \\
\text { science }\end{array}$ & $\begin{array}{l}\text { Chemical } \\
\text { Engineering }\end{array}$ & $\begin{array}{l}\text { Energy } \\
\text { Engineering }\end{array}$ \\
\hline $\begin{array}{l}\text { Technologica } \\
\text { I }\end{array}$ & $90 \%$ & $81 \%$ & $76 \%$ & $75 \%$ & $85 \%$ & $79 \%$ \\
\hline $\begin{array}{l}\text { Natural and } \\
\text { Health } \\
\text { sciences }\end{array}$ & $7 \%$ & $8 \%$ & $15 \%$ & $12 \%$ & $15 \%$ & $21 \%$ \\
\hline Others & $3 \%$ & $11 \%$ & $9 \%$ & $13 \%$ & $0 \%$ & $0 \%$ \\
\hline
\end{tabular}




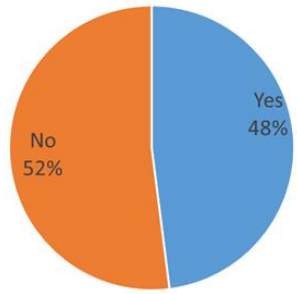

Computer Science

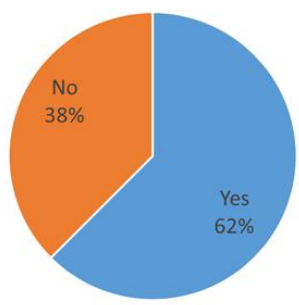

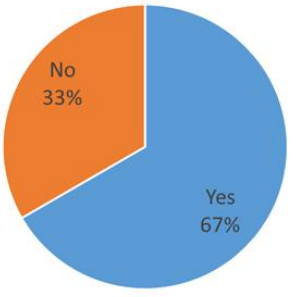

Chemical Engineering

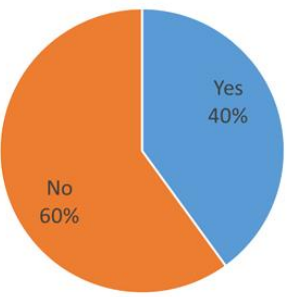

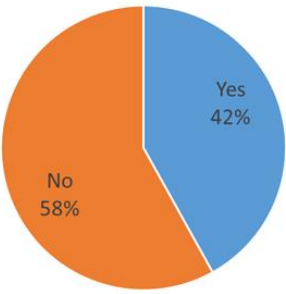

Energy Engineering

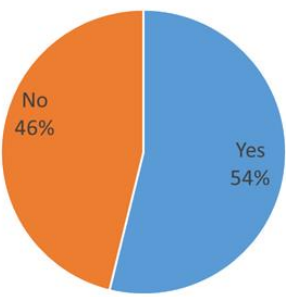

Figure 3. Problems with the timing between complementary

The next key question is "In some of the courses studied in the first year, some concepts were required previously in another subject?", which enables to detect problems in the synchronization between complementary courses. As shown in Figure 3, the average percentage is lower than the lack of concepts detected, but still very high. Again, the subjects indicated by the students are essentials in the curriculum of any engineer, as we can see in Figure 4.

Industrial Technology Engineering

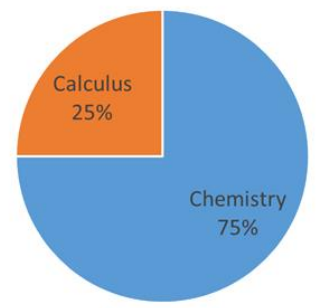

Computer Science

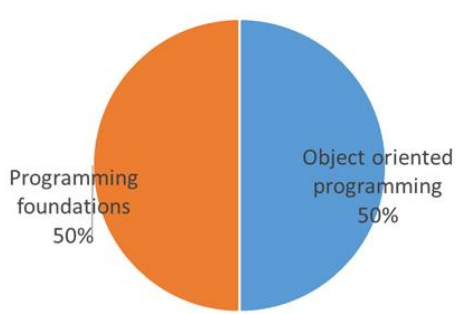

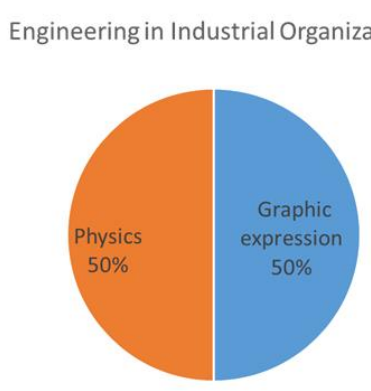

Chemical Engineering

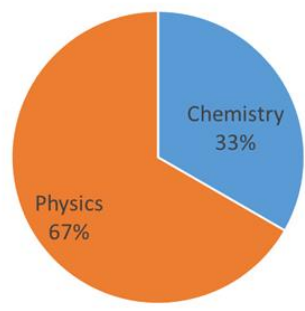

Telecommnication Engineering

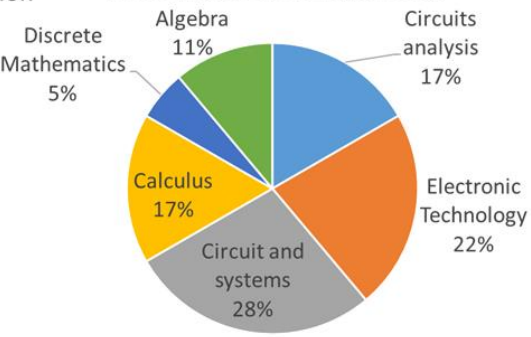

Energy Engineering

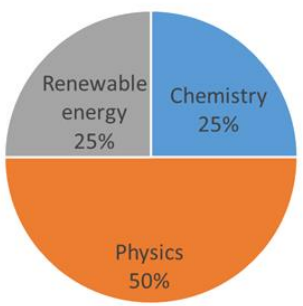

Figure 4. Courses with overlaps

\section{CONCLUSIONS}

One of the conclusions reached after the analysis of the questions presented to the students is that the syllabus in the first year of the degree of the engineering careers under evaluation should be updated 
and reorganized more efficiently because presents topics with duplicities/overlapping and synchronization problems.

At the same time, it was detected a lack of the required background knowledge in key subjects such as Chemistry and Physics. The source of this problem could be that these subjects are not mandatory in the high school modalities taken by the engineering students. We strongly recommend to reconsider the compulsory subject in high school. Finally, we recommend to reinforce mathematical concepts in preentry University courses.

\section{ACKNOWLEDGEMENTS}

This paper has been supported by the University of Malaga through the Education Innovation Project PIE17-050. I Plan Propio Integral de Docencia. Universidad de Málaga.

\section{REFERENCES}

[1] M. Tam, "Measuring Quality and Performance in Higher Education", Quality in Higher Education, vol. 7, no. 1, pp. 47-54, 2001

[2] N.M. Punyanunt-Carter, T.R. Wagner, "Communication based emotional support differences between professors and teaching assistants", Education, vol. 125, no. 4, pp. $569-574$

[3] J. O'Flaherty, C. Phillips, "The use of flipped classrooms in higher education: A scoping review", Internet and Higher Education, vol. 25, pp. 85-9, 2015

[4] J. Casas Anguita, J.R. Repullo Labrador, J. Donado Campos et Al. "La Encuesta Como Técnica De Investigación. Elaboración De Cuestionarios Y Tratamiento Estadístico De Los Datos (I)", Atención Primaria, 31, 8, 527-538, 2003

[5] C. Cea D’Ancona. "Métodos de encuesta: teoría y práctica, errores y mejora", 2004. 